\title{
Abstract \\ Impact of bronchial asthma on lifestyles in children with bronchial asthma in a tertiary care unit
}

Umashankar $\mathrm{N}^{1}$, Azmy $\mathrm{AM}^{1 *}$, Balasubramaniyam $\mathrm{M}^{1}$

${ }^{1}$ Department of Paediatrics, Faculty of Medicine, University of Jaffna, Sri Lanka

\begin{abstract}
Background

This study was conducted to evaluate the impact of bronchial asthma on lifestyles in bronchial asthmatic children from Jaffna, Sri Lanka.

Method

A prospective cross sectional descriptive institutional based study was done during 1st of April to 30th of June 2015 in the Paediatric respiratory clinic at Professorial unit, Teaching hospital, Jaffna among the children who were diagnosed as bronchial asthma \& on inhaled corticosteroids for more than 3 months duration. Data was collected using pretested interviewer administered questionnaire \& was analysed using SPSS version 20.

\section{Results}

A total of 60 children were studied during the study period. Mean age was $7.2 \pm 4$ years. Female: Male ratio 1.22: 1 . During the previous three months of data collection $55 \%$ had good control, $25 \%$ had poor control \& $5 \%$ had very poorly controlled asthma. $5 \%$ needed the systemic steroids to control the symptoms. Mean duration of steroid usage was 15 months. Only $16(26.7 \%)$ children had exercise induced asthma. Life style restriction was found in 34 $(56.67 \%)$ children for ice cream \& chilled foods. $18(30 \%)$ of the patients restricted bathing. Crab restriction was found in $25(41.6 \%)$ patients. There was no association between severity of asthma \& lifestyle restriction.

\section{Conclusions}

Even when the asthmatic symptoms are under control parents impose life style restriction in their children with bronchial asthma.
\end{abstract}

Key words: Bronchial asthma; Lifestyle restriction; Teaching hospital Jaffna

Copyright: $\odot 2015$ Umashankar $\mathrm{N}$ et al. This is an open access article distributed under the Creative Commons Attribution License, which permits unrestricted use, distribution, and reproduction in any medium, provided the original work is properly cited.

\footnotetext{
*Correspondence : azmyafza88@gmail.com
}

Cite this abstract as: Umashankar N, Azmy AM, Balasubramaniyam M. Impact of bronchial asthma on lifestyles in children with bronchial asthma in a tertiary care unit. Anuradhapura Medical Journal 2015;9 (Supp):S39. DOI: DOI: http://dx.doi.org/10.4038/amj.v9i2Supp.7588 
